university hospitals and also at greater municipal hospitals, there is in progress an action of schooling and demonstrating. To these lectures the physicians at the university and municipal hospitals and also the directors of the Public Health Services of the various regions are invited. In the near future there will come into existence in Poland some new rehabilitation units with paraplegia rehabilitation units, first of all in Silesia, Gdansk and Poznan. A sport section of paraplegics has been created at the sports club of the Invalid Co-operative Society. In the near future the start of the building of an establishment is expected comprising living-rooms connected with the Invalid Co-operative Societies.

Comprehensive research work is planned, the aim of which is primarily the activation of the medical treatment programme, shortening the duration of rehabilitation and speeding up the evaluation of the social prognosis. In view of the living conditions in Poland, in cases of young people coming from villages there is a need to change their living conditions, especially their homes and to create appropriate economic groups, connected with the Invalid Co-operatives. To this purpose the necessary means are being prepared by the Invalid Co-operatives so that in the near future colonies will be organised in greater district towns.

Research on orthopaedic devices, especially for use by tetraplegics, will be started in the not too distant future with a view to inserting electrodes in the region of peripheral nerves and stimulating muscles. We are convinced that cross-skin electro-stimulation with the possibility of eliciting appropriate movements will show new ways leading to a combination of electronics with suitable mechanical or pneumatic devices. Co-operation has been initiated with the Institute of Automatics at the Polish Academy of Science and with the Chairs of Automatics of the Technical High School of Warsaw University.

Work on wheelchairs for paraplegics allows us to hope that this programme will be solved in the near future. We received for clinical use universal wheelchairs adapted for difficult terrain and also for taking part in sport proper to paraplegics.

For the third time a Polish team has come to the International Stoke Mandeville Games. This year our team is much bigger than in the previous years, and also includes women. Our team has been trained for the competition in the Warsaw Olympic Centre, together with normal sportsmen. This is a sign of great understanding in Poland of sport for the handicapped as an essential part of their social rehabilitation.

\title{
ORGANISATION OF A SPINAL INJURY UNIT WITHIN A REHABILITATION CENTRE
}

\author{
By T. M. GregG, M.D., F.R.C.P.I. \\ National Medical Rehabilitation Centre, Dublin
}

THIS problem and c' Minister's advisory body - the National Organisation for Rehabilitation (N.O.R.). 
In planning the development of health services, it is important to plan on grouping of facilities and not by title of diagnosis.

The need for a specialised team to treat the immediate result of spinal injury and for continuity through the various stages of rehabilitation back into the community, has created the need for doctors to come forward and give their lives to this work. In effect, a new speciality has evolved to deal with this and allied problems. I believe this trend will become more and more apparent over the years, with the development of centres and the appropriate specialists, primarily interested in the rehabilitation of the severely disabled of different types. These centres should bring together the best of the available urological, neurosurgical and orthopaedic talents, rather than develop as a particular interest of one of the longer standing specialities.

The population in Southern Ireland is about 2.8 million, with little heavy industry and, as yet, limited mining. Experience has shown that we get about 35 spinal iniuries with cord involvement per year. A sanatorium in Dublin was converted in 196I into the National Medical Rehabilitation Centre, with extensive additions of gymnasium, hydrotherapy and workshops. An order of nuns, the Sisters of Mercy, run the Centre. Specialised teams were trained at Stoke Mandeville for spinal injuries and Roehampton, as well as in Germany and the U.S., in limb manufacturing and fitting. Some American ideas on Vocational Assessment were introduced. The Centre ( 120 beds) copes with the problem of spinal injury, limb fitting and a wide scattering of other physical disabilities. There are about 45 beds for spinal injuries, 25 for limb fitting, 6 for vocational assessment and the rest for neurological, rheumatic and orthopaedic cases. These groups require common facilities, gymnasia, workshops, A.D.L. training, social and sporting facilities and a school for children and their close association gives mutual aid. For instance, the Medical Officer to the Limb Fitting Unit has been responsible for the 'Urovac'-a very satisfactory device for incontinent women and has more recently developed the 'Rotarest' bed for spinal injury cases. This keeps the patient in constant motion, rotating him on an axis trom about $70^{\circ}$ on one side to $70^{\circ}$ on the other and completely saves the need for the traditional 'turns'. The patient is more comfortable, the staff have less work, physiology is easier and direct, and other complications are less. The special techniques of nursing care of the skin and supervision of bladder and bowel developments for the paraplegic are of great value in the severe cases of Parkinsonism, multiple sclerosis, rheumatic and orthopaedic disabilities.

We have been fortunate in obtaining consultants from leading neurosurgical urological, orthopaedic and other specialised centres. We have three whole-time medical officers and three part-time local general practitioners, whom we sent for training to Stoke Mandeville. In addition to a large staff of nurses and orderlies, we have 12 physiotherapists, 6 occupational therapists, 2 speech therapists, 2 medical social workers, 3 vocational school instructors and one primary school teacher. We find the key to success with this wide variety of personnel is the Case Conference, where the treatment and progress of each individual is studied at intervals, and three such sessions are held weekly.

The Centre is closely associated with the N.O.R., one of whose functions it is to operate the vocational assessment, training and placement services for disabled persons. The vocational assessment problems are admitted to the Centre for 
study. This service, which has 3 psychologists and I5 whole-time placement officers, is directly integrated with the Centre. Vocational assessment and guidance conferences are held at the Centre twice weekly and all the disabled in the educational or working age-groups are studied and guided.

Soon after opening the spinal injuries unit, we had a case of a fractured cervical spine, transported, partially sitting, with very little support. Ever since, we have made a rule of sending out a doctor, a nurse and an orderly to bring in each new case. This group leaves immediately the local hospital notify them of a case and they are competent to put in traction and bring the case in. This provision of an expert team as a service to our colleagues, emphasising how important it is to get the cases in quickly, resulted in much good-will and the early transfer of cases. Initially, it proved a strain in the more distant areas in the West of Ireland, which in some cases might be six hours' distance by car and often took a further eight hours to get the case to the Centre by local ambulances, which were not always satisfactory.

The Department of Defence rose to the occasion and now, on request, an Army helicopter lands at the Centre within 15 minutes of telephoning, flies the doctor and nurse to the patient and flies back with the patient on a specially designed stretcher, together with the team. This has enabled us to pick up a badly shocked complete $\mathrm{C}_{5}$ lesion at the side of the road among the hills in West Kerry, which is about 250 miles from the Centre-transfuse her at the roadside and have her in bed in the spinal unit in Dublin less than five hours after her accident.

I need not emphasise to this Society the desirability of getting spinal injury cases to a spinal unit, without delay. Of the 146 new traumatic cases admitted by us since I96I, I know of eight cases where the paralysis started atter the accident or became much more complete after the accident, in six or seven of these cases while the patient was in the general hospital. Provision of a service results in co-operation from our colleagues, and of the last 50 admissions, 29 were in the Centre within 24 hours of the accident, from all parts of the country. A further 12 were in within three days. We get a predominance of cervical lesions - IO9 cases, including 28 complete lesions and 8I incomplete. There were 22 thoracic-I4 complete and 8 incomplete, and I5 lumbar-2 complete and I3 incomplete. The large figure of incomplete cervical cases is evidence of the early transfer to specialised units of many cases which previously the general hospital would have been tempted to retain.

The Rehabilitation Centre is closely identified with the medical schools in undergraduate and post-graduate teaching. It also works closely with the two schools of physiotherapy. The new college for training of occupational therapists in Ireland is in the Centre. It is also active in the field of nursing training. In future, all nurses going into the Public Health and District Nursing Services, i.e. providing the home nursing service, will spend part of their training course in the Centre learning the problems of home nursing of paraplegics and allied cases. Every ambulance driver and attendant in the country is being trained at the Centre in his approach to suspected spinal injuries in accident cases.

Our latest venture is to purchase a nearby property as a hostel for the younger paraplegics who can go to work and as a cervical long-care centre for those who cannot go home. We hope to open this within a few months. A voluntary body, 
the Irish Wheelchair Association, has been formed now for some years with the aim of helping in social activities, sport and problems such as provision of transport for paraplegics. We have much to be thankful for to Stoke Mandeville, and in particular to Sir Ludwig Guttmann and Dr. Walsh, in the progress that we have made to date.

I am of the opinion that our planning has been correct and the right place to put a spinal injuries unit is in the main medical rehabilitation centre within the orbit of the main general and teaching hospital group.

\title{
ORGANISATION AND FUNCTION OF THE FRENCH SWISS PARAPLEGIC CENTRE
}

\author{
By Ala IN B. Rossier, M.D. \\ From the Paraplegic Centre of the University Institute for Physical Medicine \\ and Rehabilitation, Beau-Séjour Hospital, Geneva, Switzerland
}

\section{INTRODUCTION}

BEFORE starting our description, it seemed necessary to us to give a short historical notice about the basic facts which led to the construction of our centre.

About Io years ago, serious consideration was given to the possibility of building a paraplegic centre in Switzerland as it was increasingly realised how much such an institution was needed. At that time spinal cord patients were taken care of for the most part in neurosurgical and orthopaedic hospitals which were neither equipped and fitted for the treatment of such patients nor trained in the necessary team-work. In 1956 a committee was founded to study this problem, thanks to the voluntary participation of paraplegics, doctors, lawyers, hospital directors, representatives of insurance companies, the Government, Army and paramedical personnel. Finally it was decided to build this centre in Basle, a German-speaking canton, close to the French and German borders. Federal and private funds as well as contributions from each canton were expected to finance the centre. However, as this project was encountering difficulties in its realisation and was progressing slowly, Geneva canton, which was reorganising the Department of Physical Medicine and Rehabilitation of its University Hospital decided in 1963 to build its own paraplegic centre which was opened two years later in November 1965. As a next important step, with the agreement of the Federal Organisation on Social Insurance it was decided by medical and political authorities in Geneva canton not to restrict this centre only to the inhabitants of this canton, but also to open it to patients from other Frenchspeaking regions. It is scheduled in the near future to increase the present 20 beds capacity of the centre to 40 beds in order to be able to cope with the demand of the other French-speaking cantons. The Centre in Basle, which has been opened in June 1967, will take care of patients from German-speaking regions. From a medical, psychological and demographic point of view, such a solution with two Centres seems to be favourable. 